\title{
SIMULATION STUDY ON SOLIDIFICATION OF INITIAL SHELL OF SLAB IN CONTINUOUS CASTING MOLD
}

\author{
WEIQIANG WANG, ZHENSHAN ZHANG \\ and GUANGWU AO \\ Applied Technology School \\ University of Science and Technology Liaoning \\ Anshan 114051, Liaoning \\ P. R. China \\ e-mail: lnaszzs@163.com
}

\begin{abstract}
The quality of continuous casting billet has a significant influence on the quality of continuous casting billet, and the initial state of continuous casting is determined by the initial state of continuous casting. In this paper, a continuous casting model is established. The heat transfer law, temperature field and solid fraction of initial slab shell in continuous casting mold is obtained by the finite element analysis software PROCAST.
\end{abstract}

\section{Introduction}

Longitudinal cracks in continuous casting slab are important defects that affect the quality of continuous casting slabs. The slight one can be fined to be a qualified product, but the serious one will lead to leakage or waste products, which will greatly increasing the production cost [1]. The longitudinal crack of the slab is mainly determined by the heat transfer

Keywords and phrases: continuous casting, initial shell solidification, numerical simulation.

Received December 30, 2017

(ㄷ) 2018 Scientific Advances Publishers 
and solidification process of molten steel in the mold [2]. The heat transfer of the mold is the most important sector in the cooling and solidification process of continuous casting.

It affects the surface quality of the casting slab and the productivity of the casting machine directly [3]. When the molten steel is solidified into the shell in the mold, it moves forward. If the heat of the steel can be passed away in time, the shell will grow gradually thickens. The strength of shell out of mold is strong enough to withstand the molten steel pressure, slab edge crack or air gap can be pretended. But if the heat cannot be pass away in time, the shell is relatively thin, there will be crack in the weak area. And the situation even will cause the leaking by the molten steel pressure [4]. In a word, due to uneven heat transfer and uneven solidification, it is easy to cause slab air gap, cooling and solidification speed in gap part is slower than other parts, and crystalline structure is coarser, which has strong sensitivity to cracks [5]. Longitudinal cracks on the surface of continuous casting slab are formed near the meniscus of mold and expand in the 2 nd cold region. So it is caused by the solidification behaviour of molten steel in mold [6]. In this paper, the solidification of the initial shell of continuous casting slab is studied by numerical simulation.

\section{Principles in the Model}

In this simulation, two-dimensional slices and travelling pattern are adopted. In addition, the heat transfer of the casting direction is ignored. Molten steel flow is set as incompressible flow. The thermal conductivity is isotropic. The thermal physical properties of steel are only related to temperature. Considering the effect of continuous casting molten steel flow on heat transfer, it is assumed that the thermal conductivity for liquid thermal is 5 times than that of conductivity for absolute [7].

The heat transfer control equation is used in the calculation as following:

$$
\rho c \frac{\partial T}{\partial t}=\frac{\partial}{\partial x}\left(\lambda \frac{\partial T}{\partial x}\right)+\frac{\partial}{\partial y}\left(\lambda \frac{\partial T}{\partial y}\right)
$$


In the equation:

$T$ is the temperature $\left({ }^{\circ} \mathrm{C}\right)$;

$\rho$ is the liquid steel density $\left(\mathrm{kg} / \mathrm{m}^{3}\right)$;

$\lambda$ is the thermal conductivity, $\mathrm{W} /\left(\mathrm{m}^{* 0} \mathrm{C}\right)$;

$c$ is the specific heat, $\mathrm{J} /(\mathrm{kg} * \mathrm{~K})$.

The equation for heat flux between liquid steel and mold in the contact area is:

$$
q_{1}=h_{1} \times\left(T_{s t}-T_{c u}\right)
$$

In the equation:

$q_{1}$ is the heat flux between liquid steel and mold, $\mathrm{W} / \mathrm{m}^{2}$;

$h_{1}$ is the interface heat transfer coefficient between liquid steel and mold, $\mathrm{W} /\left(\mathrm{m}^{2} \bullet \mathrm{K}\right)$;

$T_{s t}$ is the temperature of liquid steel, ${ }^{\circ} \mathrm{C}$;

$T_{c u}$ is the temperature of the mold copper plate, ${ }^{\circ} \mathrm{C}$.

The equation for heat flux of air gap formed from shell's shrinkage is:

$$
q_{2}=\frac{\lambda_{1}}{\delta_{1}} \times\left(T_{s t}-T_{c u}\right)+\varepsilon \times C b \times\left[\left(\frac{T_{s t}}{100}\right)^{4}-\left(\frac{T_{c u}}{100}\right)^{4}\right] .
$$

In the equation:

$q_{2}$ is the heat flux of air gap formed from shell's shrinkage, $\mathrm{W} / \mathrm{m}^{2}$;

$\lambda_{1}$ is the air thermal conductivity, $\mathrm{W} /(\mathrm{m} \bullet \mathrm{K})$;

$\delta_{1}$ is the air gap thickness, m;

$C b$ is the blackbody radiation coefficient, $5.68 \mathrm{~W} /\left(\mathrm{m}^{2} \bullet \mathrm{K}^{4}\right)$;

$\varepsilon$ is the exterior blackness. 
The equation for the heat transfer flux density of cooling water outside copper plate of the mold is:

$$
q_{3}=h_{2} \times\left(T_{c u}-T_{w a}\right),
$$

where $q_{3}$ is the heat transfer flux density of cooling water outside copper plate of the mold, $\mathrm{W} / \mathrm{m}^{2}$;

$T_{w a}$ is the cooling water temperature, ${ }^{\circ} \mathrm{C}$;

$T_{c u}$ is the temperature of the mold copper plate, ${ }^{\circ} \mathrm{C}$;

$h_{2}$ is the heat transfer coefficient of cooling water, $\mathrm{W} /\left(\mathrm{m}^{2} \bullet \mathrm{K}\right)$.

\section{Structure of the Model and the Initial Condition}

In the simulation, the continuous casting billet section is $1400 \mathrm{~mm} \times$ $200 \mathrm{~mm} \times 1000 \mathrm{~mm}$. The model of the slab is shown in Figure 1 .
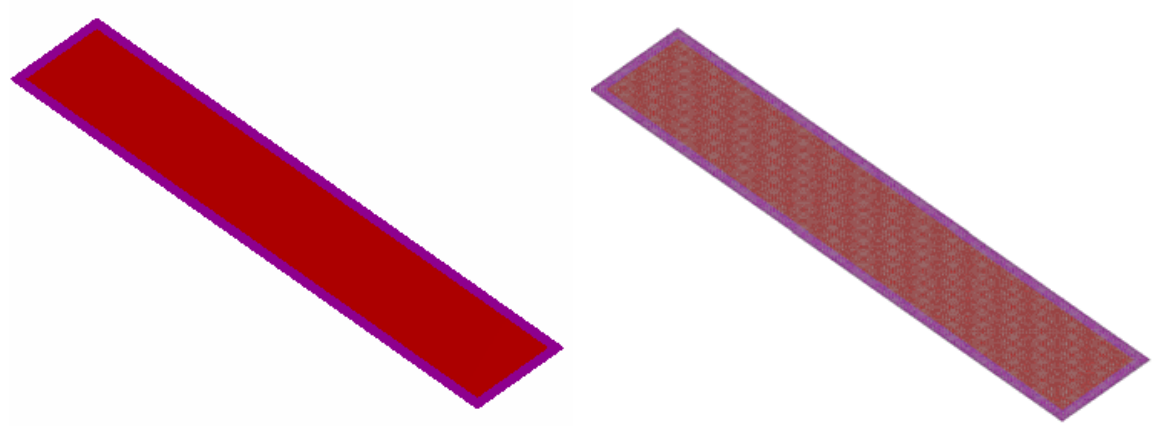

Figure 1. The model of the slab and the mesh.

In this paper, the pouring temperature of molten steel is $1540^{\circ} \mathrm{C}$ and the cooling water temperature is $35^{\circ} \mathrm{C}$. 
The chemical composition of the steel is shown as shown in Table 1.

Table 1. The chemical composition of the steel

\begin{tabular}{ccccc}
\hline $\mathrm{C}$ & $\mathrm{Si}$ & $\mathrm{Mn}$ & $\mathrm{P}$ & $\mathrm{S}$ \\
\hline 0.17 & 0.35 & 1.4 & 0.03 & 0.03 \\
\hline
\end{tabular}

\section{Analysis of the Results}

\subsection{Analysis of temperature field results of slab}

Figure 2 is the temperature field result of slab section. It can be seen that the slab solidified gradually due to the water cooling effect of the mould. And the temperature decreases larger at corner area than that in the center area of wide and narrow face of slab. This is because the heat transfer of molten steel at corners is characterized by both wide surface heat flow and narrow direction heat flow.

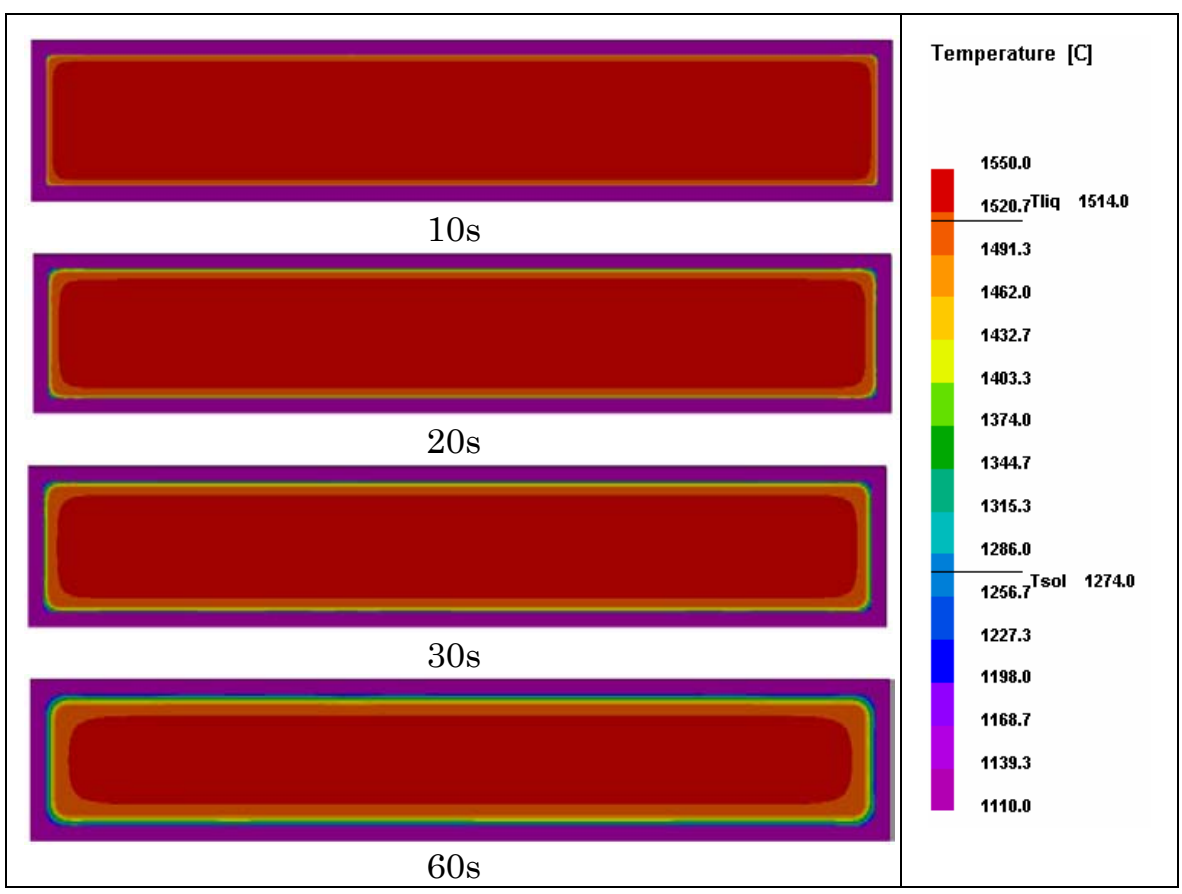

Figure 2. The change of temperature field of continuous casting slab. 
Figure 3 is the temperature field of the local magnification of the corner. From the figure, we can see that the phenomenon of extrapolation of high temperature isotherm in the wide and narrow side area of the slab near the corner, so that the thickness of the shell in the area is smaller than that of other area.

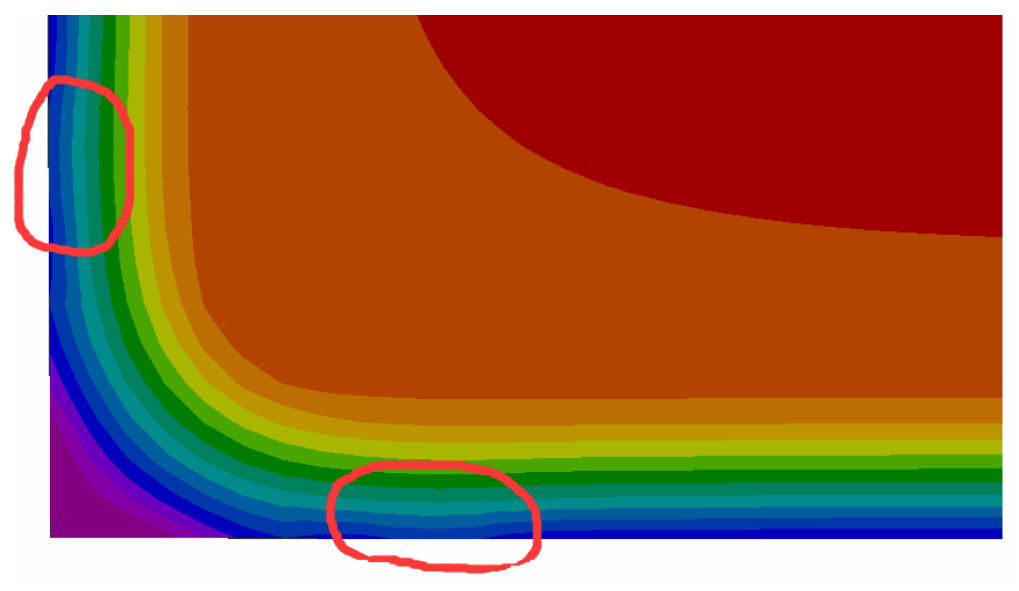

Temperature [C]

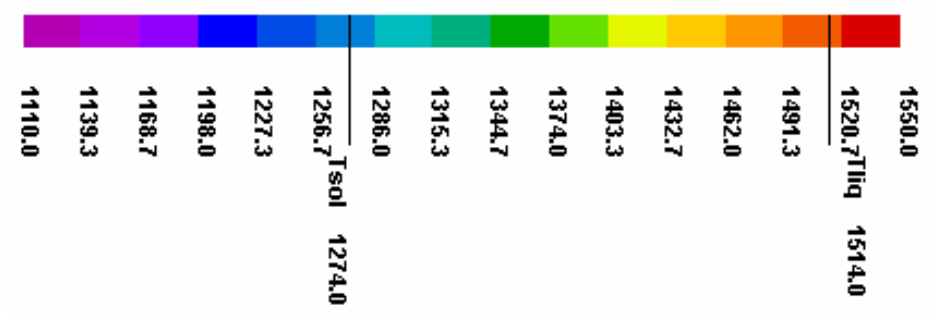

Figure 3. The temperature field of enlarged view at the area of near corner.

\subsection{Analysis of surface temperature distribution of wide side of slab}

Figure 4 is the curve of surface temperature distribution of wide side of slab. It can be seen from the figure that the temperature of the surface of the shell is uneven when the slab begins to solidify, and the temperature in the near corner region is more prominent. With the passage of time, the trend of this temperature distribution becomes more 
and more obvious. After statistical calculation of data, the variance of wide surface temperature distribution is 84.33 at $10 \mathrm{~s}, 530.91$ at $20 \mathrm{~s}$, 667.34 at $30 \mathrm{~s}$, and 826.95 at $60 \mathrm{~s}$. When the slab is at the end of mold, the maximum temperature is $1328.93^{\circ} \mathrm{C}$, the minimum temperature is $1083.43^{\circ} \mathrm{C}$ and the average temperature is $1305.42^{\circ} \mathrm{C}$.

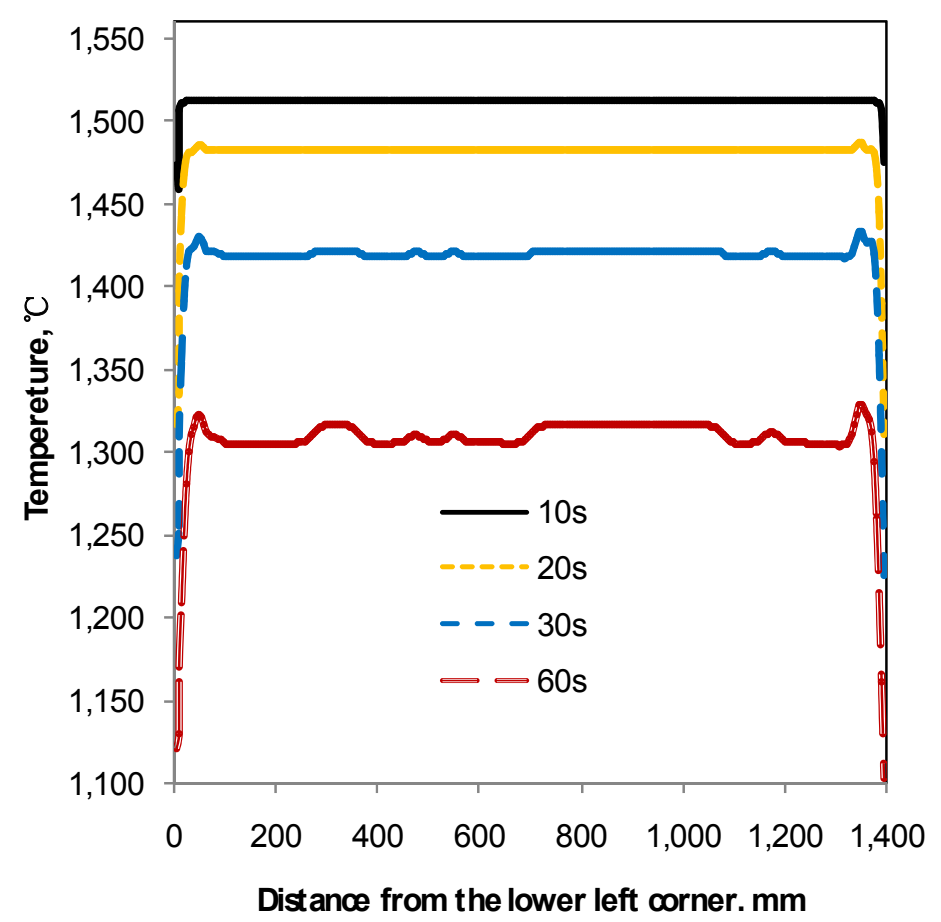

Figure 4. Curve of surface temperature distribution of wide side of slab.

\subsection{Analysis of displacement state of nodes during solidification of slab}

Figure 5 is the composite displacement of slab nodes at the end of the mold. The figure shows the displacement of the nodes in solidified shell is not uniform. The displacement of the corner is the largest, which solidified firs because of the two-dimensional heat transfer. And the faster the solidification speed is, the larger the shrinkage of the shell is. The displacement of each node in the wide face is not uniform, the reason 
is that the air gaps between shell and mold copper are randomly generated, and the heat transfer condition of the air gap is more worse obviously than other area. And thus, the displacement of these nodes is smaller.

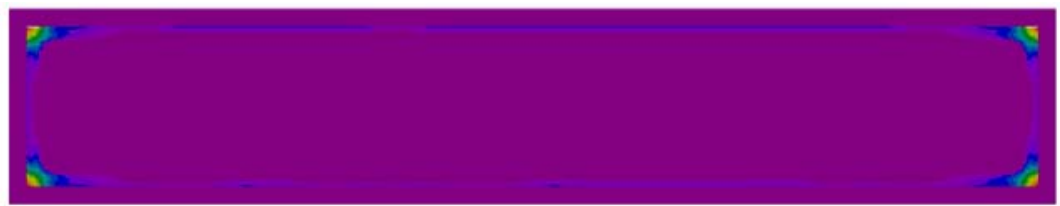

\section{Total Displacement [cm]}

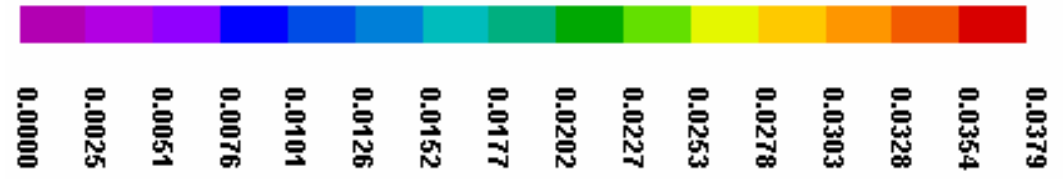

Figure 5. Composite displacement of slab nodes at the end of the mould.

\section{Conclusion}

Because of the two-dimensional heat transfer, the corner heat dissipate quickly and the solidification amount is large. The temperature reduction rate of the corner is faster than the center of the wide surface and the center of the narrow surface.

In the area near the corner, the thickness of the "near corner zone" shell is thiner than that of the adjacent area, which is predicted to be the prone area of the crack.

When the initial shell is formed, the air gap is generated, which leads to the uneven state of solidified shell. The state will remain and become stronger with time. 


\section{References}

[1] Jing Zhao, Xin-gang Zhen, Zhi-yuan Zhu et al., Formation mechanism and control method of longitudinal corner crack on slab with chamfering mold, Chinese Journal of Iron and Steel 50(7) (2015), 43-47.

DOI: 10.13228/j.boyuan.issn0449-749x.20140701

[2] Fei-fei Ren, Hui Zhang, Wei-ning Wang et al., Numerical simulation of actual temperature field for chamfered mold copper, Chinese Journal of Iron and Steel 50(4) (2015), 27-33.

DOI: 10.13228/j.boyuan.issn0449-749x.20140485

[3] N. Triolet, K. Poelmans, P. Mabelly et al., Prevention of corner cracks in slab continuous casting, Rev. Mét. Paris, 106(11) (2009), 508-517.

DOI: https://doi.org/10.1051/metal/2009083

[4] H. Nakato, M. Ozawa, K. Kinoshita et al., Factors affecting the formation of shell and longitudinal cracks in mold during high speed continuous casting of slabs, Transactions of the Iron and Steel Institute of Japan 24(11) (1984), 957-965.

DOI: https://doi.org/10.2355/isijinternational1966.24.957

[5] J. W. Cho, T. Emi, H. Shibata et al., Heat transfer across mold flux film in mold during initial solidification in continuous casting of steel, ISIJ International 38(8) (1998), 834-842.

DOI: https://doi.org/10.2355/isijinternational.38.834

[6] J. K. Brimacombe and K. Sorimachi, Crack formation in the continuous casting of steel, Metallurgical Transactions B 8(2) (1977), 489-505.

DOI: $10.1007 / \mathrm{BF} 02696937$

[7] Wei-biao Li, Fang Wang, Feng-sheng Qi et al., Mathematical model on steel stripfeeding of mold in continuous casting process, Acta Metallurgica Sinica 43(11) (2007), 1191. 